\title{
KAJIAN UMUR DAN MEDIA PEMBERSIHAN TELUR TERHADAP KUALITAS PENETASAN AYAM KAMPUNG
}

\author{
Roi Mustakim¹), Sri Sukaryani²), Engkus Ainul Yakin ${ }^{3)}$ \\ 1,2),3) Fakultas Pertanian, Prodi Peternakan, Universitas Veteran Bangun Nusantara, Jl. Letjend S. \\ Humardani No 1 Jombor Sukoharjo, Telp (0271) 593156, \\ Penulis korespondensi : Sri Sukaryani \\ email: srisukaryani@gmail.com
}

\begin{abstract}
Abstrak
Penelitian ini bertujuan untuk mengetahui waktu optimal penyimpanan telur tetas dan media pembersihan telur terhadap berat tetas dan daya tetas ayam kampung. Materi penelitian menggunakan telur tetas sebanyak 180 butir. Design percobaan menggunakan RAL pola faktorial, faktor pertama adalah faktor umur telur tetas, terdiri dari umur 3 hari (A1), umur 6 hari (A2), dan umur 9 hari (A3). Faktor kedua adalah media pembersihan telur tetas, terdiri dari media pembersihan dengan alkohol $70 \%$ (B1) dan dengan air hangat $60{ }^{\circ} \mathrm{C}$ (B2), masing-masing kombinasi perlakuan di ulang sebanyak 2 kali. Data yang terkumpul dianalisis secara statistik menggunakan Rancangan Acak Lengkap (RAL) pola faktorial. Bilamana terdapat perbedaan, di lanjutkan dengan uji Duncan't Multiple Range Test (DMRT). Hasil penelitian menunjukkan bahwa umur telur berpengaruh secara nyata terhadap berat tetas ayam kampung, dengan rata-rata nilai berat tetas dicapai oleh perlakuan A2 (45,83 g) disusul kemudian oleh A1 (44,35 g) dan A3 (43,97 g), sedangkan media pembersihan telur menunjukkan berpengaruh tidak nyata terhadap berat tetas ayam kampung. Rata-rata nilai berat telur pada perlakuan B1 dan B2 masing-masing sebesar 44,43 g dan 45,00 g. Tidak terdapat interaksi antara umur telur dan media pemberihan telur terhadap berat tetas ayam kampung. Umur telur menunjukkan berpengaruh sangat nyata terhadap daya tetas, dengan rata-rata daya tetas tertinggi pada perlakuan A1 (83,72\%) kemudian A2 $(56,33 \%)$ dan A3 $(32,80 \%)$, namun media pembersihan telur menunjukkan berpengaruh nyata terhadap daya tetas telur ayam kampung, rata-rata pada perlakuan B2 $(62,64 \%)$ dan B1 $(52,59 \%)$ adapun diantara umur telur dan media pembersihan telur tidak terdapat interaksi. Kesimpulan dari penelitian ini adalah umur telur berpengaruh sangat nyata terhadap berat tetas dan daya tetas ayam kampung, sedangkan media pembersihan telur berpengaruh nyata terhadap daya tetas dan berpengaruh tidak nyata terhadap berat tetas ayam kampung.
\end{abstract}

Kata kunci: berat tetas, daya tetas, media pembersihan, umur telur

\begin{abstract}
This research aims to determine the optimal storage time for hatching eggs and the media for cleaning eggs against hatching weight and hatchability of native chickens. This research material uses 180 hatching eggs. The experimental design used a factorial of completely randomized design, the first factor was the age of the hatching eggs, consisting of 3 days (A1), 6 days (A2), and 9 days (A3). The second factor is the media for cleaning hatching eggs, consisting of cleaning media with 70\% alcohol (B1) and warm water at $60 \circ \mathrm{C}$ (B2), each treatment combination is repeated 2 repetitions. The collected data were analyzed statistically using a factorial completely randomized design. If there are differences, continue with the Duncan't Multiple Range Test (DMRT). The results showed that egg age had a significant effect on the hatching weight of native chickens, with the average hatch weight value achieved by treatment A2 (45.83 g) followed by A1 (44.35 g) and $A 3(43.97 \mathrm{~g})$. , while the media for cleaning eggs showed no significant effect on the hatching weight of native chickens. The average egg weight values in treatment B1 and B2 were $44.43 \mathrm{~g}$ and $45.00 \mathrm{~g}$, respectively. There is no interaction between egg age and egg feeding media on the hatching weight of native chickens. Egg age showed a very significant effect on hatchability, with the highest average hatchability in treatment $A 1$ (83.72\%) then A2 (56.33\%) and A3 (32.80\%), but the media for cleaning eggs showed a significant effect. on the hatchability of native chicken eggs, the average treatment was B2 (62.64\%) and B1 (52.59\%), while there was no interaction between the age of the eggs and the media for cleaning the eggs. The conclusion of this study was that egg age had a very significant effect on hatching weight and hatchability of native chickens, while the media for cleaning eggs had a significant effect on hatchability and had no significant effect on hatching weight of native chickens.
\end{abstract}

Keywords: hatch weight, hatchability, cleaning medium, egg age 


\section{PENDAHULUAN}

Telur secara alami disiapkan untuk menunjang kehidupan serta perkembangan embrio dengan sempurna. Telur selain dibungkus dengan kulit keras yang berfungsi sebagai pelindung, juga dilengkapi dengan bahan makanan yang lengkap (Muchtadi et al, 2010).

Peternak terutama peternak rakyat jika akan melakukan penetasan telur, diawali dengan tindakan pengumpulan telur terlebih dahulu sampai telur jumlah telur mencukupi kapasitas mesin tetas, karena peternak dalam mendapatkan telur tidak sekaligus, sehingga telur yang akan ditetaskan umumnya memiliki umur yang berbeda.

Keberhasilan usaha penentasan sebagian besar dapat dilihat dari fertilitas dan daya tetasnya. Salah satu faktor yang dapat mempengaruhi fertilitas dan daya tetas adalah umur telur tetas. Menurut Winarno dan Koswara (2002), umur telur tetas yang semakin meningkat akan menurunkan kualitas telur karena penguapan $\mathrm{CO}_{2}$ dan $\mathrm{H}_{2} \mathrm{O}$. Menurunnya kualitas telur akan menghambat perkembangan embrio sehingga dapat menurunkan fertilitas dan daya tetas.Telur akan menurun daya tetasnya bila periode penyimpanan sebelumnya lebih dari 7 hari.

Umur telur tetas juga akan berpengaruh pada susut tetas dan bobot tetas. Telur yang disimpan terlalu lama dapat menyebabkan terjadinya penguraian zat organik (Soebagyo, 1981 disitasi Iskandar, 2003). Penguraian zat organik tersebut menyebabkan penyusutan bobot telur yang berdampak pada penurunan bobot tetas.

Sebelum ditetaskan dalam mesin tetas, telur tetas perlu dibersihkan terlebih dahulu, agar telur terbebas dari kontaminasi mikroorganisme yang terbawa sejak ovoposition (peneluran). Media pembersihan yang dianjurkan adalah dengan menggunakan media pembersih berupa alkohol $70 \%$, tetapi peternak ayam kampung yang pada umumnya masyarakat pedesaan, penggunaan alkohol dianggap akan menambah biaya penetasan, sehingga dapat dipilih media pembersihan yang ekonomis dan aman, yaitu dengan menggunakan air hangat dengan suhu $60^{\circ} \mathrm{C}$.

Penelitian ini bertujuan untuk mengetahui waktu optimal penyimpanan telur tetas dan media pembersihan telur terhadap berat tetas dan daya tetas ayam kampung

\section{BAHAN DAN METODE Bahan}

Bahan yang digunakan dalam penelitian adalah 180 butir telur ayam kampung dengan umur $3 \mathrm{hr}, 6 \mathrm{hr}$ dan 9 hr, alkohol $70 \%$ dan air hangat (suhu $60^{\circ} \mathrm{C}$ ). Peralatan yang digunakan meliputi mesin tetas kapasitas 100 butir, candler, eggtray.

\section{Metode}

Penelitian ini menggunakan metode eksperimen dengan desain perobaan RAL pola faktorial. Faktor pertama adalah umur telur tetas (A1 umur $3 \mathrm{hr}, \mathrm{A} 2$ umur $6 \mathrm{hr}$ dan A3 umur $9 \mathrm{hr}$ ), faktor kedua adalah media pembersihan (B1 media pembersihan berupa alkohol $70 \%$ dan $\mathrm{B} 2$ adalah air hangat $60^{\circ} \mathrm{C}$ ), jumlah ulangan sebanyak 2 kali. Data yang terkumpul dianalisis secara statistik menggunakan RAL faktorial dan apabila diantara perlakuan terjadi perbedaan maka dilakukan uji lanjut menggunakan uji Duncan't Multiple Range Test (Mulyono, 2011)

\section{Variabel Pengamatan}

Variabel yang diamati antara lain adalah daya tetas dan berat tetas

\section{HASIL DAN PEMBAHASAN Pengaruh Perlakuan Terhadap Daya Tetas}

Tabel 1.Pengaruh Umur Telur dan Media Pembersihan Telur Tetas terhadap Daya tetas Ayam Kampung (\%)

\begin{tabular}{cllll}
\hline $\begin{array}{c}\text { Media } \\
\text { Pembersihan }\end{array}$ & \multicolumn{3}{c}{ Umur Telur Tetas } & $\begin{array}{l}\text { Rata- } \\
\text { rata }\end{array}$ \\
\cline { 2 - 4 } & $\begin{array}{c}\text { A1 } \\
\text { (umur 3 } \\
\text { hr) }\end{array}$ & $\begin{array}{l}\text { A2 } \\
\text { (umur } \\
\mathbf{6 ~ h r})\end{array}$ & $\begin{array}{l}\text { A3 } \\
\text { (umur } \\
\mathbf{9} \text { hr) }\end{array}$ \\
\hline B1 & $75,125^{\mathrm{a}}$ & $51,89^{\mathrm{a}}$ & 30,76 & $52,59^{\mathrm{b}}$ \\
\hline B2 & $92,305^{\mathrm{a}}$ & $60,77^{\mathrm{b}}$ & 34,845 & $62,64^{\mathrm{b}}$ \\
\hline Rata-rata & $83,72^{\mathrm{a}}$ & $56,33^{\mathrm{b}}$ & $32,80^{\mathrm{c}}$ & \\
\hline
\end{tabular}

Keterangan: Huruf yang berbeda pada baris yang sama menunjukkan berbeda sangat nyata $(P<0,01)$

Nilai rata-rata daya tetas ayam kampung yang berasal dari telur umur $3 \mathrm{hr}(\mathrm{A} 1), 6 \mathrm{hr}$ 
(A2) dan 9 hr (A3) adalah 83,72\%; 56,33\% ; $32,80 \%$, sedang daya tetas yang penetasannya menggunakan media alkohol $70 \%$ (B1) dan air hangat $60{ }^{\circ} \mathrm{C}$ (B2) adalah $52,59 \%$ dan $62,64 \%$. Data selengkapnya tertera pada tabel 1. Berdasarkan tabel 1 setelah diuji statistik menunjukkan bahwa umur telur berpengaruh sangat nyata terhadap daya tetas telur ayam kampung $(P$ $<0,01)$. Sedangkan media pembersihan telur menunjukkan hasil berpengaruh secara nyata terhadap daya tetas telur ayam kampung ( $P$ $<0,05)$, namun tidak terjadi interaksi antara umur telur tetas dan media pembersihan terhadap daya tetas telur ayam kampung $(P$ $>0,05)$. Perlakuan A1 menghasilkan daya tetas yang tertinggi $(83,72 \%)$, hal ini karena karena pada umur telur tetas 3 hari telur masih dalam keadaan segar. Telur yang masih segar memiliki pori - pori kerabang telur yang lebih kecil dibandingkan dengan telur yang sudah lama disimpan. Pori-pori kerabang telur yang lebih kecil lebih dapat mencegah masuknya bakteri kedalam telur, sehingga kualitas isi telur dapat dipertahankan. Seperti yang diungkapkan oleh Rasyaf (2000), semakin lama telur tetas disimpan maka pori-pori kulit telur akan semakin lebar, sehingga memungkinkan penetrasi bakteri ke dalam telur tetas semakin besar yang mengakibatkan kualitas telur tetas semakin menurun dan meningkatkan susut tetas. Menurut Effendy (2008) Alkohol 70\% merupakan cairan yang mengandung $70 \%$ etil alkohol $\left(\mathrm{CH}_{3} \mathrm{CH}_{2} \mathrm{OH}\right)$ dan $30 \%$ air. Etil alkohol (etanol) membunuh bakteri pada cangkang telur, cangkang yang kotor bisa menjadi sumber bakteri Salmonella $s p$ Bakteri ini bisa mencemari putih telur, kuning telur. Demikian pula air hangat $60^{\circ} \mathrm{C}$ dapat membunuh bakteri Salmonella $s p$. (Saraswati, 2012).

\section{Pengaruh Perlakuan terhadap Berat tetas Ayam Kampung}

Data berat tetas ayam kampung selama penelitian tertera pada tabel 2. Hasil uji statistik menunjukkan bahwa umur telur berpengaruh secara nyata terhadap berat tetas ayam kampung $(P<0,05)$, tetapi media pembersihan telur menunjukkan berpengaruh secara tidak nyata dan tidak terjadi interaksi antara umur telur tetas dan media pembersihan terhadap berat tetas telur ayam kampung $(P>0,05)$. Tabel 2.Pengaruh Umur
Telur dan Media Pembersihan Telur Tetas terhadap Berat Tetas Ayam Kampung ( g )

\begin{tabular}{|c|c|c|c|c|}
\hline \multirow{2}{*}{$\begin{array}{l}\text { Media } \\
\text { Pembersihan }\end{array}$} & \multicolumn{3}{|c|}{ Umur Telur Tetas } & \multirow{2}{*}{$\begin{array}{l}\text { Rata- } \\
\text { rata }\end{array}$} \\
\hline & $\begin{array}{l}\text { A1 } \\
\text { (umur } \\
3 \mathrm{hr} \text { ) }\end{array}$ & $\begin{array}{l}\text { A2 } \\
\text { (umur } \\
6 \mathrm{hr} \text { ) }\end{array}$ & $\begin{array}{l}\text { A3 } \\
\text { (umur } \\
9 \mathrm{hr} \text { ) }\end{array}$ & \\
\hline B1 & 44,24 & $45,03^{b}$ & 44,02 & $44,43^{b}$ \\
\hline B2 & 44,46 & $46,63^{a}$ & 43,93 & $45,00^{b}$ \\
\hline Rata-rata & $44,35^{b}$ & $45,83^{a}$ & $43,97^{b}$ & \\
\hline Kete & $<0, c$ & $\begin{array}{l}\text { berbe } \\
\text { hunjuk } \\
\text { ) }\end{array}$ & $\begin{array}{l}\text { ada ba } \\
\text { berbec }\end{array}$ & $\begin{array}{l}\text { yang } \\
\text { nyata }\end{array}$ \\
\hline
\end{tabular}

Berat tetas pada perlakuan A2 (45,83 gr) berbeda lebih tinggi dibandingkan dengan A1(44,35 gr) dan A3 (43,97 gr), sedangkan A1 dan A3 memberikan hasil berat tetas yang tidak berbeda nyata dan A3 menunjukkan berat tetas yang cenderung paling rendah. Hal ini diduga disebabkan oleh susut tetas yang berbeda, berat tetas dipengaruhi oleh susut tetas. Terjadinya penyusutan berat telur tetas selama penetasan dapat dilihat dari berkurangnya berat telur akibat terjadinya penguapan cairan dan gas-gas organik dari dalam telur. Semakin berat telur yang akan ditetaskan, maka berat tetas akan semakin besar. Hal ini sesuai dengan pendapat Rahayu (2005) yang menyatakan bahwa anak itik yang dihasilkan dari penetasan telur sangat dipengaruhi oleh berat telur karena telur mengandung nutrisi seperti vitamin, mineral dan air yang dibutuhkan untuk pertumbuhan selama pengeraman. Nutrisi ini juga berfungsi sebagai cadangan makanan untuk beberapa waktu setelah anak ayam menetas. Berat telur yang seragam akan menghasilkan anak itik hasil penetasan yang seragam pula.

\section{SIMPULAN}

Hasil penelitian ini dapat disimpulkan sebagi berikut :

a. Umur telur 3 sampai 9 hari berpengaruh sangat nyata terhadap daya tetas dan berat tetas ayam kampung 
b. Media pembersihan yang berupa alkohol $70 \%$ dan air hangat dengan suhu $60^{\circ} \mathrm{C}$ berpengaruh nyata terhadap daya tetas dan berpengaruh tidak nyata terhadap berat tetas ayam kampung.

c. Umur telur dan media pembersihan tidak berinteraksi terhadap daya tetas dan berat tetas ayam kampung.

\section{DAFTAR PUSTAKA}

Effendy. 2008. Teori VSEPR, Kepolaran, dan Gaya Antar Molekul. Malang: Bayumedia Publishing

Iskandar. R. 2003. Pengaruh Lama Penyimpanan Telur dan Frekuensi Pemutaran Telur terhadap Daya Tetas dan Mortalitas Telur Puyuh. Skripsi. FP- USU. Medan

Muchtadi, T.R., Sugiyono, M., dam Ayustaningwarno, F. (2010). Ilmu Pengetahuan Bahan Pangan. Jakarta: ALFABETA, CV

Rahayu, H.S. 2005. Kualitas Telur Tetas Dengan Waktu Pengulangan Inseminasi Buatan Yang Berbeda. skripsi. Fakultas Kedokteran Hewan. Institut Pertanian Bogor: Bogor.

Rasyaf, M. 2000. Pengelolaan Penetasan. Cetakan ke-2. Kanisius. Yogyakarta

Saraswati, D. (2012). Uji Bakteri Salmonella sp. Pada Telur Bebek, Telur Puyuh dan Telur Ayam Kampung yang di Perdagangkan di Pasar Liluwo Kota Gorontalo. Laporan Penelitian. Fakultas Ilmu-Ilmu Kesehatan dan Keolahragaan Universitas Negeri Gorontalo.

Winarno, F.G. dan S. Koswara. 2002. Telur: Komposisi, Penanganan, dan Pengolahannya. M-Brio Press. Bogor. 